Egypt. Acad. J. biolog. Sci., 3(1):65-71 (2011)

Email: egyptianacademic@yahoo.com

Received: 11/12/2011
C. Physiology \& Molecular Biology

ISSN: 2090-0767

www.eajbs.eg.net

\title{
Evolutionary Genetic Analysis of the cytochrome b gene variation in the Salmo trutta fario with other salmons
}

\author{
Abolhasan Rezaei ${ }^{1}$ and Sheyda Akhshabi ${ }^{2}$ \\ 1-Department of Genetics-School of Basic Science, Islamic Azad University \\ Tonekabon Branch,Iran. \\ 2- Young Researchers Club, Tonekabon Branch, Islamic Azad University, \\ Tonekabon, Iran. \\ a.rezaei@tonekaboniau.ac.ir
}

\begin{abstract}
PCR amplification and direct sequencing of regions of the cytochrome b mitochondrial genes was carried out on Iranian populations of the salmo trutta fario species. Samples of salmo trutta fario were also examined and used as an out group in the phylogenetic analysis. Results based on $1192 \mathrm{bp}$ indicated differentiation between fario morphs from Iran and other salmonids also Iran and other country had collected. Despite the large phenotypic differences within salmonids, very low genetic variation was found. On the basis of the cytochrome $b$ sequences studied, Salmo carpio and Salmo fibreni, which have been described as good species, there were high homology between salmo trutta fario, salmo trutta and salmo trutta caspius (99\%), but regards salmo salar the rate of homology $93 \%$. Regards salmo trutta fario, in hatchery trout has not red colour strips time of hatchery in salmo trutta fario whereas has a bluish grey body colour, However, they are larger than Atlantic salmon, salmo trutta caspius and salmo trutta, more regular in shape, and less intensively pigmented, moreover there are red spots are always observed in populations, however, the shape and size of salmo trutta fario is different with salmo trutta caspius and salmo trutta but the among of homology were high (99\%). The salmo trutta fario and salmo trutta caspius are living in the Rivers of North of Iran that connected to Caspian Sea; perhaps these species with themselves has been conjugated, and regards salmo salar is living in the Atlantic Ocean and other Sea and Rivers connected to it, that so far to salmo trutta fario populations in Iran. However we cannot report exactly that how much homology between sequences, because already there are not complete sequence in GeneBank regards salmo trutta caspius and salmo trutta fario.
\end{abstract}

Keywords: Salmo trutta fario, DNA sequencing, cytochrome b.

\section{INTRODUCTION}

There are different methods for identifying and authenticating for fish and fishery product, specially, DNA methods and molecular testing for increasing products. (Gill, et al., 1997; Rasmussen et al., 2008). In related to, there are wide range of approached of varying technical sophistication and cost which exploit diagnostic polymorphism within mitochondrial DNA and nuclear DNA genomics. Different molecular methods including RFLP-PCR techniques, SSCP-PCR techniques also sequencing of DNA fragments (Carrera et al., 2000; Abercrombie et al., 2005; Lee et al., 2004), approaches have been successfully implemented to identify partially degraded and otherwise compromised products (Dalvin et al., 2010). In general, mitochondrial DNA transmitted maternal traits, mtDNA targeted methods have predominated in such studies, because of the general 
robustness and higher cellular copy number of mtDNA compared with nDNA.(Mackie et al., 1999).In this paper we used PCR and direct sequencing techniques to compare and analyzing segments of cytochrome b DNA sequence variation in the salmo trutta fario and observed among morphologically distinct salmo trutta fario, salmo trutt, salmo trutta caspius and salmo salar populations. Regards to cytochrome b, Bernatchez et al., (1992), studied on the variation of it gene, also, they studied segments of the mitochondrial control region, with this results, we can discussed the congruence in phylogenetic relationships among salmo trutta fario populations inferred from the analysis of coding and noncoding regions of the segments of cytochrome $b$ gene. Regarding genetic variations salmonids, were studied brown trout that was found substantial genetic differentiation, as revealed by protein variation is found between native Mediterranean and Atlantic populations (Kerieg \& Guyomard 1985; Guyomard 1989; Persa et al.1994). Also, Largiader et al., (1996), had reported there are common phenotype of the fluviatile ecotype of brown trout, salmo trutta $f$. fario. According to local fisherman, the striped trout represent the native form in the Doubs, whereas the fario phenotype originates from introductions of hatchery trout. In this research our aims to study among of homology between salmo trutta fario, salmo trutta caspius salmo salar and salmo trutta by cytochrome $b$ gene, also the rate of relationships between salmo trutta fario and other salmonids for cytochrome $b$ gene.

\section{MATERIALS AND METHODS} Sample collections, DNA extraction and gene amplification and sequence analysis:

Animals: Salmo trutta fario were obtained from the Rivers of Tonekabon Iran, in the summer of 2011. All fish were approximately $1 \mathrm{~kg}$ in size. Species used in this study salmo trutta fario.DNA extracted from muscles samples was used to obtain sequence from the salmo trutta fario.

Cytochrome b gene. cytochrome b gene sequences were amplified from salmo trutta fario. DNA was extracted from tissue muscles according to the method of Sambrook et al., (1998). The concentration of DNA samples was determined with a DNA spectrophotometer under wave length of A260/280 nanometer.The PCR and sequencing primers used based on consensus sequences of salmonid species. PCR amplifications were carried out in $25 \mu \mathrm{l}$ volumes containing 1X PCR buffer, $6 \mathrm{ng} / \mathrm{pL}$ template DNA, 0.025 units/pL Taq polymerase (Bethesda Research Laboratories), $200 \mathrm{uM}$ each deoxynucleotide-triphosphate (dNTPs), and approximately $25 \mathrm{pmol} / \mu 1$ of each amplification primer. Amplifications were carried out primarily in a Perkin Elmer 9600 thermal cycler. PCR amplifications were performed with 35 cycles. Denaturation, annealing and extension times were varied according to the thermal cycler used and the size of the expected amplification product. Primers (cytochrome b Forward and Reverse), designed to specifically amplify the cytochrome b gene, including: Forward Primer 5' GACTTGAAAAACCACCGTTG 3' and Reverse Primer 5' CTCCGATCTCCGGATTACAAGAC

3 ,were based on conserved sequences from the promoter and terminator regions identified by the alignment of cytochrome $b$ sequence data from several salmonid species. These amplification products were compared to the amplification products from a genomic DNA template using 1.5 percent agarose gel electrophoresis.

\section{Sequencing:}

For doing sequence we designed one side primer from end of the gene 
including, GTTTTCCTAAATTTCCAATTGC. By this primer amplified full length of sequence of cytochrome $b$ gene in the salmo trutta fario.

Polymerase chain reaction (PCR; Saiki et al., 1988) amplification was performed on 200-500 ng of genornic DNA template with either Ultratherm (BioiCan Scientific) or Taq (Bethesda Research Laboratories-BRL) DNA Polymerase using the reagents and instructions provided by the manufacturer. Typically, the thermal profile of a PCR consisted of 2-4 min. incubation at 94" $\mathrm{C}$, followed by 30 cycles of $30 \mathrm{~s}$ at $94^{\circ} \mathrm{c}, 30 \mathrm{~s}$ at $55^{\circ} \mathrm{c}, 60 \mathrm{~s}$ at $72^{\circ} \mathrm{c}$, followed by a $4 \mathrm{~min}$. incubation at $72^{\circ} \mathrm{c}$. PCR amplification products were prepared for sequencing by purification with DNA Clean-Up kits (Promega). Where necessary, multiple amplification products were separated by electrophoresis in low-melting-point agarose using standard methods (Sambrook et al.1989).

Amplification products were sequenced directly using either the Thenosequenase sequencing kits (Amersham United States Biochemicals).

Sequencing, electrophoresis and autoradiography were performed according to the manufacturer's instructions.

\section{Accessed in the GeneBank:}

The cytochrome $b$ gene was sequenced and deposited in GeneBank by Accession number (JN995186.1).

\section{RESULTS}

Mitochondrial sequence DNA analysis: Overall, the mitochondrial DNA genomic has a relatively high substitution rate in salmonid fishes (Thomas and Beckenbach, 1989; McKay et al., 1996). The cytochrome $b$ gene is part of mitochondrial DNA. However, approximately, the complete sequence of the cytochrome $b$ gene (1191 nt) was found to be identical between salmo trutta fario in Iran. Also observed among of variation between salmonids, including, salmo trutta caspius, salmo trutta and Salmo salar.

Variation in exon sequences of the cytochrome b gene: The DNA sequence of cytochrome $\mathrm{b}$ gene from salmo trutta fario individuals was determined. To avoid confusion about geographic origin, only wild strains from known sampling locations were analyzed. Comparison of variation within species revealed that the higher degree of homozygosity with salmonid group. Although no fixed differences were observed between salmo trutta fario and salmo salar, because the degree of variation more than other salmonids likes salmo trutta and salmo trutta caspius. However results are shown there were almost variation between salmo salar, salmo trutta caspis and salmo trutta. The sequence of the same region of the cytochrome $b$ gene was also obtained from salmo trutta fario, salmo trutta and salmo trutta caspius similar variation was detected within this gene: the ( $\mathrm{T}$ to $\mathrm{C}, \mathrm{C}$ to $\mathrm{A}, \mathrm{T}$ to $G$ and $A$ to $G$ ), repeat sequences in the full length of the sequences. There were within sequences. The repeat single nucleotides, (A to $\mathrm{G}, \mathrm{C}$ to $\mathrm{A}$ and etc.). In addition to variation in the number of repeat units in the cytochrome b gene had same with all of sequences exception salmo salar. (Fig. 1). 
Salmo trutta fario and salmo trutta caspius alignments:

s.t.f.:49 tttatttcagctcagccagccaagggggcgagaactaggaagatagtaaagtaaattac 108

s.t.c. 1053 tttatttcagctcagccggccaagggggcgagaactaggaagatagtaaagtaaattac 994

s.t.f.:109 agaggcaacttgaccgatgatgataaatgggtgttctacaggtatccctccaattcaggt 168 ||||||||||||||||||||||||||||||||||||||||||||||||| |||||||||||

s.t.c.: 993 agaggcaacttgaccgatgatgataaatgggtgttctacaggtatccccccaattcaggt 934

s.t.f.:169 gaggatcagtatgtctgctactagggttcagaataagaattgggttagggggcgaaaggt 228

||||||||||||||||||||||||||||||||||||||||||||||||||||||||||||||

S.t.c.: 933 gaggatcagtatgtctgctactagggttcagaataagaattgggttagggggcgaaaggt 874

s.t.f.:229 tagtccgcgttgcttagaggtatggaggatgggaacgactataaggaccaggatcgagaa 288

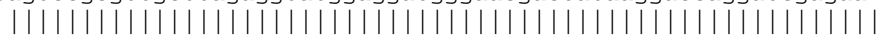

s.t.c.: 873 tagtccgcgttgcttagaggtatggaggatgggaacgactataaggaccaggatcgagaa 814

s.t.f.:289 taagagggcgagtactccgcccagcttattaggaatagagcgaaggattgcgtaggcgaa 348

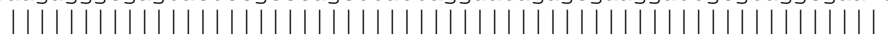
s.t.c. : 813 taagagggcgagtactccgcccagcttattaggaatagagcgaaggattgcgtaggcgaa 754

s.t.f. :349 taggaagtatcattcgggcttgatatgaggcggggtgactagggggttggcaggcgtaaa 408

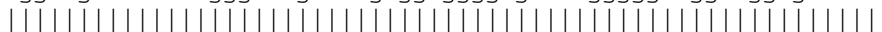

S.t.c.: 753 taggaagtatcattcgggcttgatatgaggcggggtgactagggggttggcaggcgtaaa 694

s.t.f.:409 attgtccgggtctccgaggaggttgggtgcgaacagagctaatgatgttaggccaagtag 468 ||||||||||||||||||||||||||||||||||||||||||||||||||||||||||||||||||||

s.t.c.: 693 attgtccgggtctccgaggaggttgggtgcgaacagagctaatgatgttaggccaagtag 634

s.t.f.:469 tatagctacgaatccaaggaggtctttgtacgagaagtaggggtggaatgagattttatc 528 |||||||||||||||||||||||||||||||||||||||||||||||||||||||||||||

s.t.c.: 633 tatagctacgaatccaaggaggtctttgtacgagaagtaggggtggaatgagattttatc 574

s.t.f.:529 ggcatcggagttgatacctgctgggttattagagccggtttcatgtaaaaatagaaggtg 588 |||||||||||||||||||||||||||||||||||||||||||||||||||||||||||

S.t.c.: 573 ggcatcggagttgatacctgctgggttattagagccggtttcatgtaaaaatagaaggtg 514

s.t.f.:589 gagtactgtggcagctgcaataacgaatgggaataggaagtgaaaggcgaaaaatcgtgt 648 |||||||||||||||||||||||||||||||||||||||||||||||||||||||||||||

s.t.c.: 513 gagtactgtggcagctgcaataacgaatgggaataggaagtgaaaggcgaaaaatcgtgt 454

s.t.f.:649 tagggtggcgttgtcgacagaaaatccgcctcaaattcattgtacaagggcgcctccaac 708

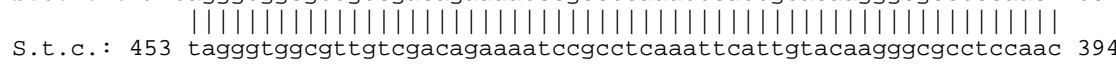

s.t.f.:709 gtatgggacagcggagagaaggtttgtaattacagtggctcctcagaaggacatctgtcc 768 |||||||||||||||||||||||||||||||||||||||||||||||||||||||||||||

S.t.c.: 393 gtatgggacagcggagagaaggtttgtaattacagtggctcctcagaaggacatctgtcc 334

s.t.f.:769 tcatggaagaacgtagcccacgaaggcggttattatagtgagaagtagcagtacgactcc 828 |||||||||||||||||||||||||||||||||||||||||||||||||||||||||||||

s.t.c.: 333 tcatggaagaacgtagcccacgaaggcggttattatagtgagaagtagcagtacgactcc 274

s.t.f.:829 gatattcaggtttctttatataggtaggaaccatagtagagtcctcgggcgatatgtat 888 |||||||||||||||||||||||||||||||||||||||||||||||||||||||||||

S.t.c.: 273 gatattcaggtttctttatataggtaggaaccatagtagagtcctcgggcgatatgtat 214

s.t.f.:889 ataaatacagataaagaagaaagatgctccgttagcgtgaatgttccggatgagtcagcc 948 ||||||||||||||||||||||||||||||||||||||||||||||||||||||||||||

s.t.c.: 213 ataaatacagataaagaagaaagatgctccgttagcgtgaatgttccggatgagtcagcc 154

s.t.f.:949 gtagctaacgtctcggcaaatgtggcaaacagaggaaaaggctgttgagatatcggaggt 1008

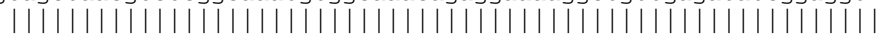

s.t.c.: 153 gtagctaacgtctcggcaaatgtggcaaacagaggaaaaggctgttgagatatcggaggt 94

s.t.f.:1009atagtgtatggctaggaagagcccggtaagaatttgggtggctagacac 1057

s.t.c.: 93 atagtgtatggctaggaagagcccggtaagaatttgggtggctagacac 45

s.t.f.: 1075caagttgcctctgtaatttactttactatcttcctaggtcttgccccttg 1125 ||||||||||||||||||||||||||||||||||||| ||| ||||||||

s.t.c. : 982 caagttgcctctgtaatttactttactatcttcctagttctcgccccttg 1032 
Salmo trutta fario and Salmo salar alignments:

s.t.f.:49 tttatttcagctcagccagccaagggggcgagaactaggaagatagtaaagtaaattac 108

||||||||||||||||||||||| |||||| || |||||||||||||||||||||||||||

s.s.: 16508 tttatttcagctcagccagccaggggggcaaggactaggaagatagtaaagtaaattac 16449

s.t.f.: 109 agaggcaacttgaccgatgatgataaatgggtgttctacaggtatccctccaattcaggt 168

|||||||| |||||| ||||| || ||||||||||| || ||||| ||||||||||||||

s.s.: 16448 agaggcaatttgaccaatgataatgaatgggtgttccacgggtatgcctccaattcaggt 16389

s.t.f.:169 gaggatcagtatgtctgctactagggttcagaataagaattgggttagggggcgaaaggt 228

s.s.: 16388 aaggattagtatgtccgctaccagggtccagaataagaattgggtgagtgggcgaaagt 16329

s.t.f.: 229 tagtccgcgttgcttagaggtatggaggatgggaacgactataaggaccaggatcgagaa 288

s.s.: 16328 ||||| ||||| || |||||||||||||||||||| |||||||||||||||||||||||||||||||

cagtcctcgttgtttagaggtatggaggatggggacgactataaggaccaggatcgagaa 16269

s.t.f.:289 taagagggcgagtactccgcccagcttattaggaatagagcgaaggattgcgtaggcgaa 348

s.s.: 16268 ||||||||||||||||||||| || || |||||||| ||||| |||||||||||||||||

s.s.: 16268 taagagggcgagtactccgcctagtttgttaggaatggagcgtaggattgcgtaggcgaa 16209

s.t.f.:349 taggaagtatcattcgggcttgatatgaggcggggtgactagggggttggcaggcgtaaa 408

||||||||||||||| |||||||||||||| || || ||||||||||||||||| |||||

s.s.: 16208 taggaagtatcattcaggcttgatatgaggtggagtaactagggggttggcaggtgtaaa 16149

s.t.f.:409 attgtccgggtctccgaggaggttgggtgcgaacagagctaatgatgttaggccaagtag 468 ||||| ||||| |||||||||||||||||| |||||||| ||||||||||||||||

s.s.: 16148 attgtctgggtccccgaggaggttgggtgcgaatagagctaaggatgttaggccaagtag 16089

s.t.f.:469 tatagctacgaatccaaggaggtctttgtacgagaagtaggggtggaatgagattttatc 528 ||| ||||| ||||| ||||||||||| || |||||||| ||||||||||||||||||||

s.s.: 16088 tatggctacaaatccgaggaggtctttatatgagaagtaagggtggaatgagattttatc 16029

s.t.f.:529 ggcatcggagttgatacctgctgggttattagagccggtttcatgtaaaaatagaaggtg 588

s.s.: 16028 ||||||||||||||| ||||||||||||||||| ||||||||||||||||||||||| ||

28 ggcatcggagttgatgcctgctgggttattagacccggtttcatgtaaaaatagaagatg 15969

s.t.f.:589 gagtactgtggcagctgcaataacgaatgggaataggaagtgaaaggcgaaaaatcgtgt 648

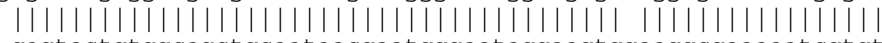

s.s.: 15968 gagtactgtggcagctgcaataacgaatgggaataggaagtggaaggcgaaaaatcgtgt 15909

s.t.f.:649 tagggtggcgttgtcgacagaaaatccgcctcaaattcattgtacaagggcgcctccaac 708 ||||||||||||||| ||||||||||| ||||||||||||||||||||||||||||| ||

s.s.: 15908 tagggtggcgttgtctacagaaatcctcctcaaattcattgtacaagggegcctcctac 15849

s.t.f.:709 gtatgggacagcggagagaaggtttgtaattacagtggctcctcagaaggacatctgtcc 768 ||| |||||||||||||| ||||||||||||||||||||||||||||||| || |||||

s.s.: 15848 gtaggggacagcggagaggaggtttgtaattacagtggctcctcagaaggatatttgtcc 15789

s.t.f.:769 tcatggaagaacgtagcccacgaaggcggttattatagtgagaagtagcagtacgactcc 828 |||||||||||||||| ||||||| |||||||||||||||||| ||||| ||||

s.s.: 15788 tcatggaagaacgtagcctacgaaggcagttattatagtgagaagtagaagtacaactcc 15729

s.t.f.:829 gatattcaggtttctttatataggtaggaaccatagtagagtcctcgggcgatatgtat 888

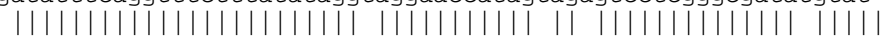

s.s.: 15728 gatattcaggtttctttatatagataggaaccataataaagtcctcgggcgatgtgtat 15669

s.t.f.:889 ataaatacagataaagaagaaagatgctccgttagcgtgaatgttccggatgagtcagcc 948

s.s.: 15668 ||||||||||||||||||||||||||||||||||||||||||||| ||||||||||||||

s.S.: 15668 ataaatacagataaagaagaaagatgctccgttagcgtgaatgttacggatgagtcagcc 15609

s.t.f.:949 gtagctaacgtctcggcaaatgtggcaaacagaggaaaaggctgttgagatatcggaggt 1008

| |||||||| ||||||||||||||||||||||||||||| |||||||||||||||||||||

s.s.: 15608 atagctaacatctcggcaaatgtggcaaacagaggaaaaagctgttgagatatcggaggt 15549

s.t.f.:1009 atagtgtatggctaggaagagcccggtaagaatttgggtggctagaca 1056

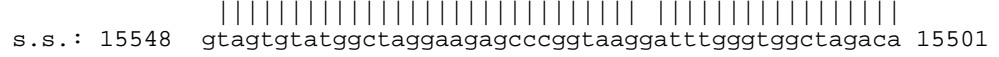

s.t.f.:1079 ttgcctctgtaatttactttactatcttcctaggtcttgccccc 1122

||||||||||||||||||||||||||||||||| |||||||||

s.s.: 16441 ttgcctctgtaatttactttactatcttcctagtccttgcccc 16484

s.t.f.:1134 agcaatttttaggagggggtgagtttt 1160

s.s.: 15425 agcaattttaggagcgggtgagttt 15399

Fig.1: DNA sequences of segments of cytochrome b gene from salmo trutta fario, salmo trutta caspius and salmo salar. There are variable positions salmo trutta fario. Including regions of repeated A to $\mathrm{C}, \mathrm{G}$ to $\mathrm{T}$ and $\mathrm{G}$ to A. Abbreviations, were, (s.t.f: salmo trutta fario), (s.t.c: salmo trutta caspius), (s.s.: salmo salar). 


\section{DISCUSSION}

Phenotypic plasticity in salmo trutta fario and most salmonid species certainly limits its utility to resolve evolutionary and phylogenetic issues (Allendorf et al., 1987; Bernatchez et al., 1992; Bernatchez, 1995). In addition, we explained phenotypic and their distribution of striped between species of salmonids and rate of relationships with salmo trutta fario populations, in related to, in the Atlantic populations there are four black strips and variable number of small irregular black, spots white halos on the body sides. (Largiader et al. 1996). Salmo trutta fario, in hatchery trout has a bluish grey body colour and no black strips, However, they are larger than Atlantic salmon, salmo trutta caspius and salmo trutta, more regular in shape, and less intensively pigmented, moreover there are red spots are always observed in populations, however, the shape and size of salmo trutta fario is different with salmo trutta caspius and salmo trutta but the among of homology were high (99\%). The salmo trutta fario and salmo trutta caspius are living in the Rivers of North of Iran that connected to Caspian Sea; perhaps these species with themselves has been conjugated, and regards salmo salar is living in the Atlantic Ocean and other Sea and Rivers connected to it, that so far to salmo trutta fario populations in Iran. However there is not any report regards complete sequence of cytochrome $b$ gene in the salmo trutta fario and salmo trutta caspius, but regards salmo salar and salmo trutta have been reported in GeneBank. So, after sequencing of complete cytochrome $b$ gene, we can exactly discuss about among of relationship between salmo trutta fario and other salmonids. Also, we should more research and using other method genetic techniques for finding ancestor of salmons specially relationships between salmo trutta fario, salmo trutta caspius, salmo trutta and salmo salar.

Sequence analysis of salmo trutta fario and among of homology with other sequences of cytochrome $b$ in salmonids: In this research, has examined variations in exonic sequence of a cytochrome $b$ gene. Analysis of the sequence of cytochrome $b$ gene that has one exon from first to end of the gene. There were some variation between salmo truutta fario and other salmonids that revealed a variable microsatellite locus within the sequence of full length. A direct, tandem repeat of a (CGT) sequence motif were observed. Also, there were tandem repeats single nucleotides including $\mathrm{A}$ to $\mathrm{C}, \mathrm{A}$ to $\mathrm{G}$ and $\mathrm{G}$ to $\mathrm{T}$, between salmo trutta fario, salmo trutta caspius and salmo trutta. Regards salmo salar the variation was more, so, the rate of variation on single nucleotides were low. We aim also research on the complete sequence of mitochondrial genomics and among relationships with mitochondrial salmo salar that reported in GeneBank.

\section{CONCLUSION}

The sequences of cytochrome $b$ gene fragment we have identified in the Salmo trutta fario, that could be a potential genetic markers for Salmonids. Differences in trait association of the genetic markers may exist among different populations. More tests are needed in other populations of bony fishes to variety associated effects of genetic marker, as well as the effects of the other polymorphisms in the mitochondrial genome. However the mitochondrial genes traits more will be transformed from maternal, So, is better the studies on the other genes markers for example growth hormone genes, microsatellites and other marker genes related, that are associated with paternal traits. 


\section{ACKNOWLEDGMENTS}

This work had financially supported by the research council of Islamic Azad University Tonekabon branch.

\section{REFERENCES}

ABERCROMBIE DL., CLARKE SC., SHIVJI MS. (2005): Global-scale genetic identification of hammerhead sharks: Application to assessment of the international fin trade and law enforcement. Cons Gens, 6,775-788.

ALLENDORF, F.W., RYMAN, N. and UTTER, F. (1987). Genetic and fishery management: past, present and future. ln: Ryman, N. and Utter, F. (eds). Population Genetics and Fishery Management, 144-160.

BERNATCHEZ L., GUYOMARD R., BONHOMME F. (1992): DNA sequence variation of the mitochondrial control region among geographically and morphologically remote European brown trout, salmo trutta populations. Molecular Ecology, 1, 161-173.

BERNATCHEZ, L. and OSINOV, A. (1995). Genetic diversity of trout (genus Salmo) from its most eastern native range based on mitochondrial DNA and nuclear gene variation. Molecular Ecology, 4: 285-297.

BROWN AHD. (1975): Samples sizes required to detect linkage disequilibrium between two or three loci.Theoretical population biology, 8, 184-201.

CARRERA E., GARCIA T., CESPEDES A., GONZALEZ I., FERNANDEZ A., ASENSIO LM., HERNANDEZ PE., MARTIN R (2008): Identification of smoked Atlantic salmon (Salmo salar) and rainbow trout (Onchorhynchus mykiss) using PCRrestriction fragment length polymorphism of the p53 gene. J AOAC Intl, 83:341-346.

GILL A. (2007): PCR-based methods for fish and fishery products authentication. Trends Food Science Technology, 18:558-566.

GUYOMARD R. (1989): Diversie genetique de la truite commune. Bulletin Francais de la Pisciculture, 314:118-135.

GUYOMARD R, (1989): Electrophoretic variation in six populations of brown trout (salmo trutta L). Canadian Journal of Genetics and cytology, 25, 403-413.

LEE JCI., TSAI LC., LIAO SP., LINACRE A., HSIEH HM. (2009): Species identification using the cytochrome $\mathrm{b}$ gene of commercial turtle shells. Forensic Science Int Genet. 6773.

MACKIE IM., PRYDE SE., GONZALESSOTELO C., MEDINA I., PEREZ-MARTIN R., QUINTEIRO J., REY-MENDEZ M.,
REHBEIN H. (1999): Challenges in the identification of species of canned fish. Trends Food Science Technology, 10:9-14.

MCKAY S.J., DEVLIN R.H., and SMITH M.J. (1996): Phylogeny of Pacific salmon and trout based on mitochondrial NADH Dehydrogenase Subunit 3 (ND3) and nuclear Growth Hormone Type2 (GH2) DNA sequences. Can. J. Fish. Aquat. Sci. 53:11651176.

PAVLOVSKI Z., MAŠIĆ B. (1994): Odnos potrošača prema živinskim proizvodima. Živinarstvo, 7-9: 77-82.

PAVLOVSKI Z. (2004): Novi propisi EU, dobrobit živine, zahtevi potrošača. Živinarstvo, 8-9, 49-58.

PERSA WR., KRIEQ F., ESTOUP A., GUYOMARD R. (1994): Diversite et gestion genetique de la truite commune: apport de letude du poymorphism des locus proteiques et microsatellites. Genetique, Selection, Evoloution, 26: 1835-2025.

RASMUSSEN RS., MORRISSEY MT. (2008): DNA-based methods for the identification of commercial fish and seafood species. Comparative Reverse Food Science Food Saf $.7: 2813$

RICE WR. (1989): Analyzing tables of statical tests. Evoloution, 43 (1): 223-225.

LARGIADER C.R. and SCHLL A. (1996): Genetic introgression between native and introduced brown trout salmo trutta L. population in the Rhone River Basin. Molecular Ecology, 5: 417-426.

SAMBROOK J., FRITSCH E.F., E.F., MANIATIS T. (1989): Molecular Cloning: A Laboratory Manual. $2^{\text {nd }}$. Cold Spring Harbor Laboratory Press, Cold Spring Harbor, N.Y.

SAIKI R.K., GELFAND DA., STOEFFEL S., SCHARF S.J., HIGUCHI R., HORN G.T., MULLIS K.B., ERLICH H.A.(1988): Primer-directed enzymatic amplification of DNA with a thermostable DNA polymerase. Sci., 239: 487-491.

THOMAS W.K., BECKENBACH A.T. (1989): Variation in salmonid mitochondrial DNA: evolutionary constraints and mechanisms of substitution. J. Mol. Evol. 29: 233-245 